\title{
Use of 3-halo-1-azaallylic anions in heterocyclic chemistry*
}

\author{
Nicola Giubellina, Wim Aelterman, and Norbert De Kimpe ${ }^{\ddagger}$ \\ Department of Organic Chemistry, Faculty of Agricultural and Applied Biological \\ Sciences, Ghent University, Coupure links 653, B-9000 Ghent, Belgium
}

\begin{abstract}
The synthetic potential of lithio 3-halo-1-azaallylic anions as building blocks in organic chemistry and especially in heterocyclic chemistry will be highlighted by the synthesis of functionalized imines, obtained after reaction of 3-halo-1-azaallylic anions with heteroatom-substituted electrophiles. Thus, the latter generated functionalized imines are suitable building blocks for the synthesis of a whole range of heterocycles and physiologically active compounds, including agrochemicals and pharmaceuticals. 3-Halo-1-azaallylic anions were used in the synthesis of $\mathrm{N}$-alkyl-3,3-dichloroazetidines, 2,3-disubstituted pyrroles, piperidines, 2-substituted pyridines, 2-alkoxytetrahydrofurans, etc., from which a large range of useful and interesting chemicals can be produced, e.g., 2-azetines and 9-alkyl2-phenyl-3a $\beta, 4,6,7,8,9,9 \mathrm{a} \beta, 9 \mathrm{~b} \beta$-octahydro-1 $H$-pyrrolo[3,4,h]quinoline-1,3-diones. The utility of the present methodology is demonstrated by the synthesis of the pheromone $(S)$-manicone, the sulfur-containing flavor compound 2-[(methylthio)methyl]-2-butenal, and some agrochemical and pharmaceutical compounds.
\end{abstract}

\section{INTRODUCTION}

$\alpha$-Heteroatom-substituted carbanions 1 (Scheme 1), stabilized by electron-withdrawing groups, are important synthons in organic chemistry [1]. Almost all combinations of heteroatoms (e.g., halogen, silicon, selenium, sulfur, etc.) and carbanion-stabilizing groups (e.g., alkoxycarbonyl, cyano, acyl, sulfonyl, sulfinyl, etc.) are useful, except the combination of halogens and acyl groups. In the latter case, $\beta$-haloenolates are difficult to handle or are not formed at all due to competition with other reactions of $\alpha$-haloketones (cf. Favorskii reaction, epoxide formation, nucleophilic substitution, dehydrohalogenation, etc.). The selective conversion of $\alpha$-haloketones into $\alpha$-haloimines and subsequent regioselective deprotonation with sterically hindered strong bases offers an attractive synthetic potential by the use of more stable 3-halo-1-azaallylic anions 5 (Scheme 1). $\alpha$-Haloimines 4 are easily accessible from $\alpha$-haloaldehydes and $\alpha$-haloketones by reaction with primary amines in the presence of drying agents such as magnesium sulfate (convenient for most aldehydes) and titanium(IV) chloride, the latter operating as activator of the carbonyl function and chemical remover of water produced during the reaction [2]. Deprotonation of $\alpha$-haloimines with strong non-nucleophilic bases like lithium diisopropylamide in tetrahydrofuran results in the formation of 3-halo-1-azaallylic anions $\mathbf{5}$, which react with electrophiles to produce substituted imines 6. If functionalized electrophiles like alkyl halides carrying heteroatoms (oxygen, nitrogen, halogen) are used, it results in the formation of highly functionalized imines 6, which are suitable building blocks for further elaboration. Alternatively, these imines $\mathbf{6}$ can be hydrolyzed to the corresponding functionalized $\alpha$-haloaldehydes or $\alpha$-haloketones 3 . These $\alpha$-haloaldehydes $\left(3 ; R^{2}=H\right)$, $\alpha$-haloketones $\left(3 ; R^{2} \neq H\right)$, or $\alpha$-haloimines $(\mathbf{6})$ are all suitable building blocks for the synthesis of heterocycles of various kinds.

\footnotetext{
*Lecture presented at the $4^{\text {th }}$ Florida Heterocyclic Conference, Gainesville, FL, USA, 10-12 March 2003. Other presentations are published in this issue, pp. 1403-1475.

${ }^{\ddagger}$ Corresponding author.
} 
<smiles></smiles>

$\mathrm{EWG}=\mathrm{COOR}, \mathrm{CN}, \mathrm{R}^{\prime} \mathrm{C}=\mathrm{O}, \mathrm{SO}_{2} \mathrm{R}^{\prime}, \mathrm{S}(=\mathrm{O}) \mathrm{R}^{\prime}, \mathrm{CONR} \mathrm{R}^{\prime \prime}, .$.

$\mathrm{X}=$ halogen, $\mathrm{SiR}_{3}, \mathrm{SeR}^{\prime}, \mathrm{SR}$, ..

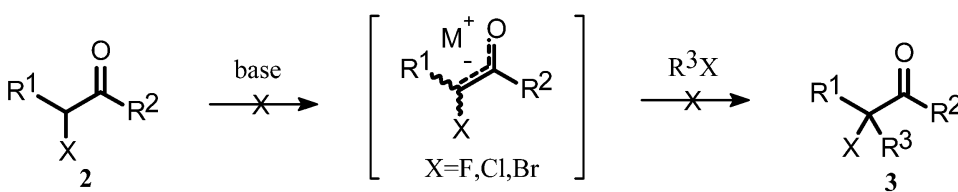

$\mathrm{RNH}_{2} \downarrow \mathrm{TiCl}_{4}$<smiles>[R]N=C([R])C([R])[V]</smiles>

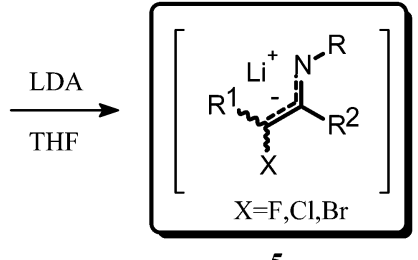

$\mathrm{H}_{3} \mathrm{O}^{+\uparrow}$

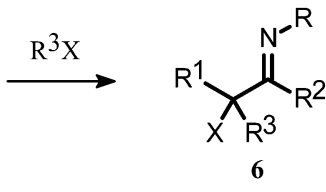

Scheme 1

As such, the detour from $\alpha$-haloaldehydes or $\alpha$-haloketones (2) to the corresponding functionalized $\alpha$-haloaldehydes or $\alpha$-haloketones 3 ( $\mathrm{R}^{3}$ carries the heteroatom functionality) via $\alpha$-haloimines offers a great potential for the synthesis of a variety of interesting compounds.

Reports so far on the use of 3-halo-1-azaallylic anions have been rather scarce. The reports include alkylations [3], reactions with aldehydes, and ketones [4]. In one case of fluorinated species, temperature-dependent regioselective alkylations to $\alpha$-fluoroimines could be achieved [5].

Because of the fact that $\alpha$-haloimines are now available by a whole range of procedures, for example, the imination process of $\alpha$-haloaldehydes or $\alpha$-haloketones (vide supra), halogenation of imines with $N$-halosuccinimides [6], retro-aldol cleavage of $\beta$-iminoesters [7], hydrodehalogenation of $\alpha$-bromo- $\alpha$-chloroimines [8], the title deprotonated species (i.e., 3-halo-1-azaallylic anions) are now easily accessible. The deprotonation with lithium diisopropylamide in THF occurs completely and under mild conditions. It concerns a completely regiospecific reaction. Contrary to the generation of enolates, the formation of 3-halo-1-azaallylic anions proceeds smoothly at $0{ }^{\circ} \mathrm{C}$. Thus, in terms of practical applications, it is important that cooling down to $-78{ }^{\circ} \mathrm{C}$ is not always necessary, although some reactions with 3-halo-1-azaallylic anions require these low temperatures (vide infra). 3-Halo-1-azaallylic anions are relatively stable at $0{ }^{\circ} \mathrm{C}$ and can be kept under these conditions in THF for several hours. In general, 3-bromo-1-azaallylic anions are much less convenient to handle than the corresponding chloro analogs due to their instability. In general, it is recommended to use 3-chloro-1-azaallylic anions in the syntheses described here. These delocalized anions react with alkyl halides exclusively at the $\beta$-carbon ( $C$-alkylation) while no $N$-alkylation has been observed so far. There is no proton transfer from the diisopropylamine, formed after deprotonation, to the anions generated. Finally, there is no condensation of 3-halo-1-azaallylic anions with the starting imine, with itself or with the end product. In other words, 3-halo-1-azaallylic anions are suitable reagents to be evaluated in organic synthesis.

In the present paper, three distinct topics of the reactivity of 3-halo-1-azaallylic anions will be highlighted. The first part concerns the alkylation with alkyl halides followed by treatment with base and hydrolysis as a three-step synthesis of $\alpha, \beta$-unsaturated carbonyl compounds. This method will be applied to the synthesis of the alarm pheromone $(S)$-manicone (Manica sp.) and the flavor compound 2-[(methylthio)methyl]-2-butenal. The second part involves the reaction of 3-halo-1-azaallylic anions with alkyl halides that are functionalized with heteroatoms. This extra functionalization in the elec- 
trophile allows further reactions to heterocycles, including piperidines, tetrahydropyridines, tetrahydrofurans, pyrrolidines, pyrroles, pyridines, azetidines, aziridines, and tetrahydroindoles. The third topic concerns the reaction of 3-halo-1-azaallylic anions with " $\mathrm{HO}^{+}$"-reagents in order to generate $\alpha$-iminoketones, which are known as flavor compounds.

\section{RESULTS AND DISCUSSION}

The synthesis of $(S)$-manicone $\mathbf{1 0}$ (Scheme 2) starts with the deprotonation of $\alpha$-chloroketimine $4 \mathbf{a}$ with LDA in THF at $0{ }^{\circ} \mathrm{C}$, followed by reaction with $(S)$-1-bromo-2-methylbutane giving $(S)$ - $\alpha$-chloroketimine 7 in $97 \%$ yield. Dehydrochlorination of the latter with potassium $t$-butoxide in DMSO at room temperature, and subsequent acid hydrolysis with oxalic acid gave a 83:17 mixture of $\alpha, \beta$-unsaturated ketones 8 and $\mathbf{9}$. This mixture of products was treated with rhodium(III) chloride in ethanol [9] to form the desired (S)-manicone $\mathbf{1 0}$ in $97 \%$ yield with an enantiomeric excess of at least $99 \%$ [10].

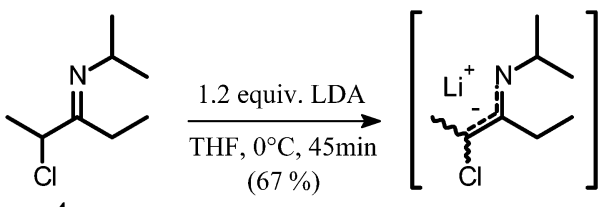

4a

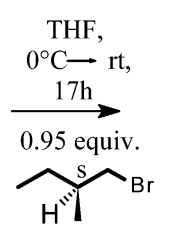

H゙リ<smiles>CCC(=NC(C)C)C(C)(Cl)C[C@@H](C)CC</smiles>

$7,97 \%$

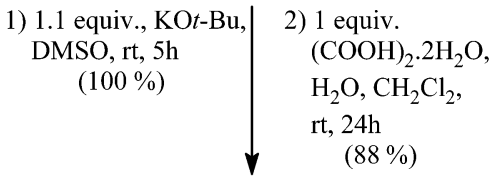

0.05 equiv.

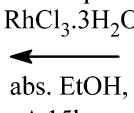

$\Delta 15 \mathrm{~h}$

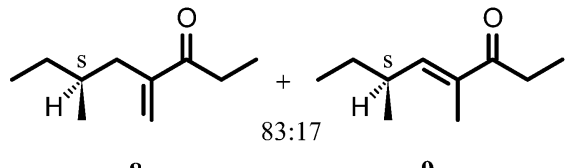

8

9

Scheme 2

2-[(Methylthio)methyl]-2-butenal 12 (Scheme 3) is a characteristic flavor compound of potato chips [11], yeast extracts [12], and cocoa [13], while it is a flavoring agent imparting a tomato and meat-
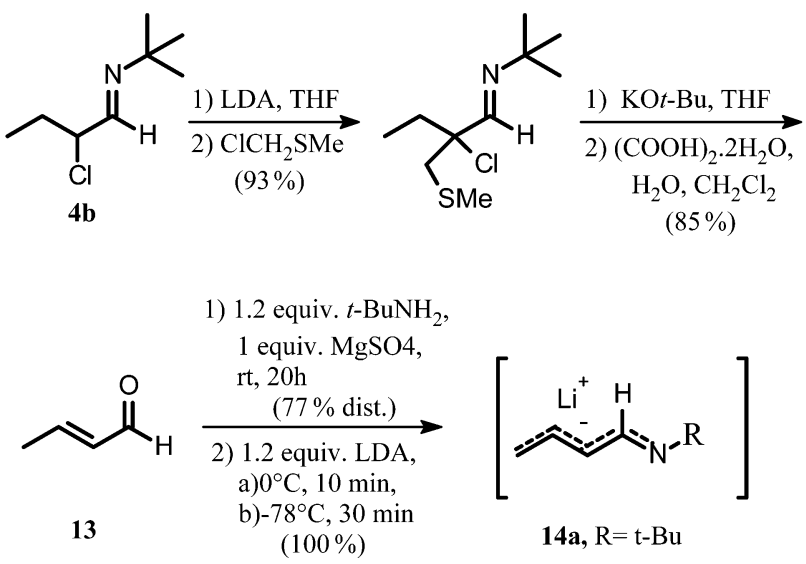

1) 1.2 equiv. $t$ - $\mathrm{BuNH}_{2}$,

equiv. $\mathrm{MgSO} 4$

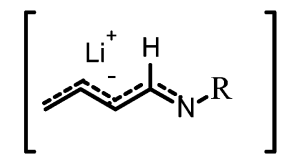

14a, $\mathrm{R}=\mathrm{t}-\mathrm{Bu}$

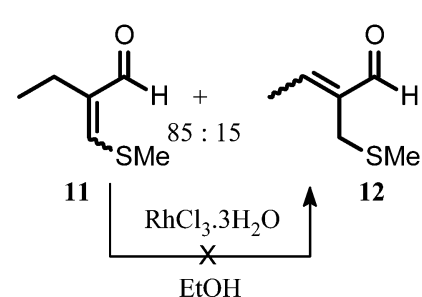

1) 1 equiv. $\mathrm{ClCH}_{2} \mathrm{SMe}$,

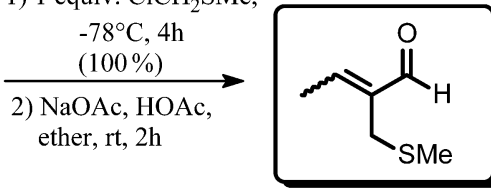

$53 \%(Z / E: 85 / 15)$

12

Scheme 3 
like flavor [14]. The classic aldol condensation of methional with acetaldehyde results in low yields of impure material [11]. Application of the same protocol as above with $\alpha$-chloroaldimine $\mathbf{4 b}$ via $\alpha$-(methylthio)methylation and subsequent dehydrochlorination and hydrolysis, afforded an 85:15 mixture of $\alpha, \beta$-unsaturated aldehydes $\mathbf{1 1}$ and 12, the ratio of which could not be changed in favor of the desired flavor compound by rhodium(III) chloride. Therefore, crotonaldehyde $\mathbf{1 3}$ was iminated with $t$-butylamine to give the corresponding enimine 20a, which was deprotonated by LDA at $-78{ }^{\circ} \mathrm{C}$ to $0{ }^{\circ} \mathrm{C}$ in THF to generate the delocalized anion 14a, which reacted at the expected $\alpha$-carbon with (chloromethyl)methylsulfide to afford the $\beta$-(methylthio)aldimine in quantitative yield. This compound was converted into the flavor compound 12 (E/Z 15:85) by sodium acetate in acetic acid in a biphase system with ether [15].

These delocalized anions 14a,b, being equivalent to 3-halo-1-azaallylic anions, were suitable for the synthesis of piperidines by condensation with 1-bromo-3-chloropropane in THF (Scheme 4). The resulting $\delta$-chloro- $\alpha$-vinylaldimines $\mathbf{1 5 a}, \mathbf{b}$, underwent reductive cyclization with sodium borohydride in methanol to 3-vinylpiperidines 16a,b.

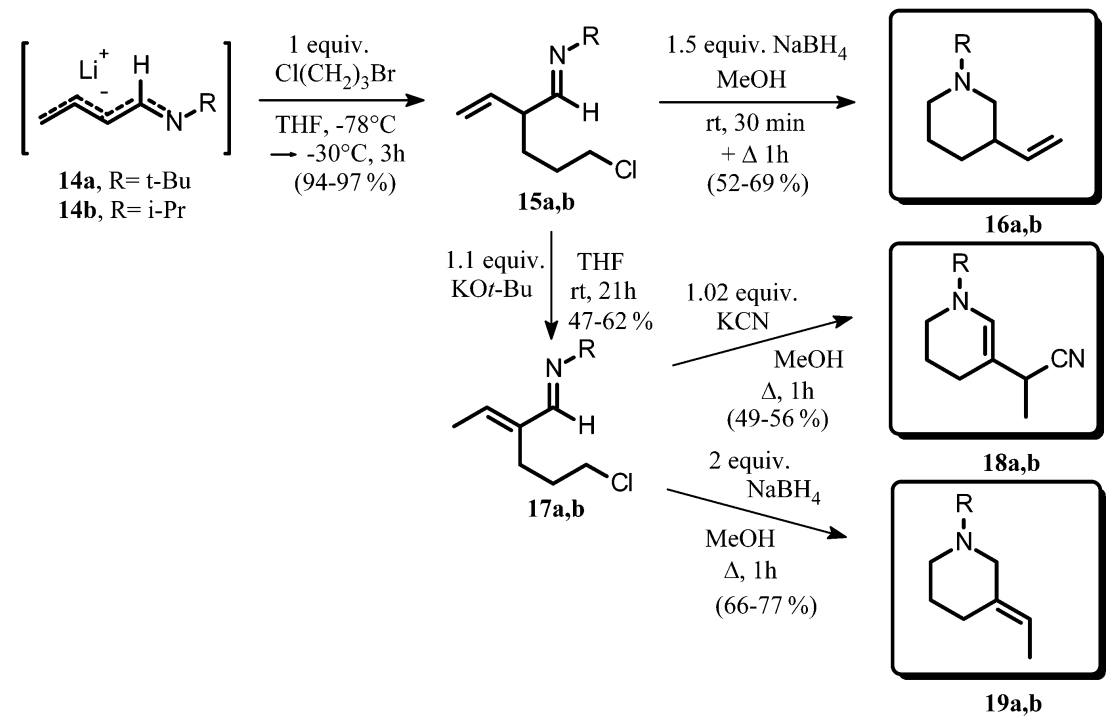

Scheme 4

Base-induced isomerization of $\mathbf{1 5 a}, \mathbf{b}$ to the conjugated imines $\mathbf{1 7} \mathbf{a}, \mathbf{b}$ gave access to tetrahydropyridines 18a,b and 3-(ethylidene)piperidines 19a,b (Scheme 4) by reaction with potassium cyanide or sodium borohydride, respectively.

An additional treatment with LDA gave rise to 1,2,3,4-tetrahydro-5-vinylpyridines 21a,b in virtually quantitative yield. Such electron-rich aminodienes $\mathbf{2 1 a}, \mathbf{b}$ smoothly undergo Diels-Alder cycloaddition with $N$-phenylmaleimide in THF under reflux to provide tricyclic diazaheterocycles 22a,b (Scheme 5).

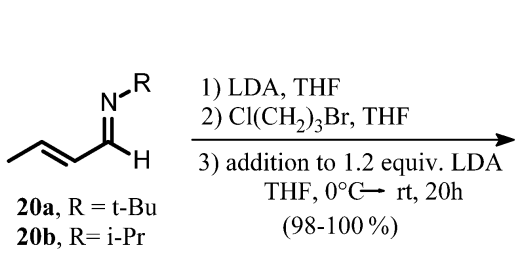

Scheme 5

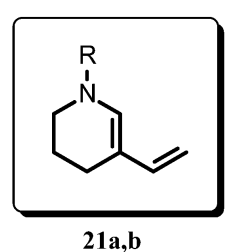

21a,b

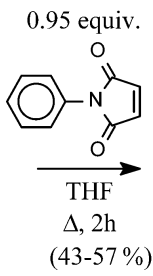

$(43-57 \%)$

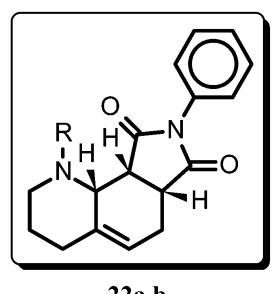

22a,b 
Regiospecific deprotonation of $\alpha$-chloroketimines $\mathbf{4 c - e}$ with LDA (Scheme 6), followed by alkylation with 2-bromoethyl trimethylsilyl ether, produced $\gamma$-trimethylsilyloxy- $\alpha$-chloroketimines 23a-c, which cyclized with alcohols to afford cis-2-alkoxy-3-aminotetrahydrofurans 25a-f in a stereospecific way after treatment with base. The mechanism was explained in terms of two possible routes involving either a trans-2-amino-3-chlorotetrahydrofuran 26a-f (Scheme 7) or intermediate 2-alkoxyaziridines or azirinium ions (27a-f). Both routes lead to a bicyclic aziridinium ion, which opens up to the final tetrahydrofurans via a hydrogen bond-guided stereospecific attack of the alcohol to the transient oxonium ion [16].

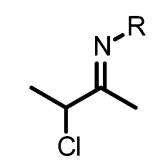

4c $\mathrm{R}=\mathrm{i}-\mathrm{Pr}$ 4d $\mathrm{R}=$ cycloHex $4 \mathrm{e}=\mathrm{s}-\mathrm{Bu}$

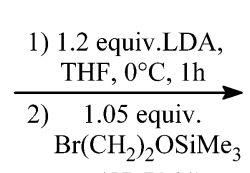

$(57-70 \%)$

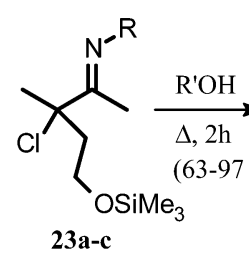

23a-c

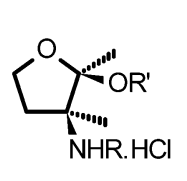

24a $\mathrm{R}=\mathrm{i}-\mathrm{Pr}, \mathrm{R}^{\prime}=\mathrm{Me}$

24b $\mathrm{R}=\mathrm{i}-\mathrm{Pr}, \mathrm{R}^{\prime}=\mathrm{Et}$

24c $\mathrm{R}=$ cycloHex, $\mathrm{R}^{\prime}=\mathrm{Me}$

24d $\mathrm{R}=\mathrm{s}-\mathrm{Bu}, \mathrm{R}^{\prime}=\mathrm{Me}$

$24 \mathrm{e} R=\mathrm{s}^{-B u}, \mathrm{R}^{\prime}=\mathrm{Et}$

24f $\mathrm{R}=\mathrm{s}-\mathrm{Bu}, \mathrm{R}^{\prime}=\mathrm{n}-\mathrm{Pr}$

Scheme 6

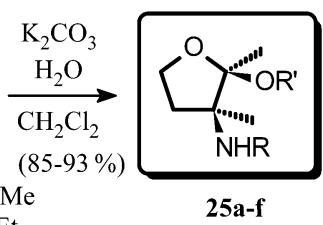

5a-f

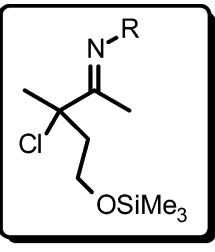

23a-c

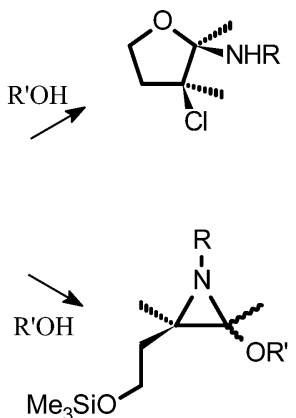

(H)<smiles>[R]N[C@]1(C)OCC[C@@]1(Cl)C[Te]</smiles><smiles>C[12CH3]</smiles><smiles>C1CCCCC1</smiles>

$27 \mathrm{a}-$

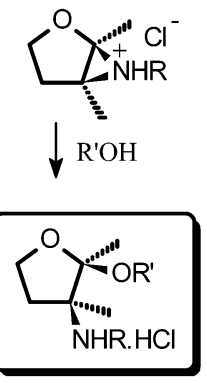

24a-f

\section{Scheme 7}

These $\gamma$-trimethylsilyloxy- $\alpha$-chloroketimines $\mathbf{2 3}$ (Scheme 8 ) are building blocks for the synthesis of aziridines and pyrrolidines. Reaction of imine 23a with sodium borohydride in methanol affords a 1:1 mixture of cis- and trans-aziridine $\mathbf{2 8}$ by reduction of the imino bond followed by intramolecular nucleophilic substitution. Ring expansion of this aziridine was performed with triphenylphosphine and $\mathrm{N}$-bromosuccinimide in THF to give a mixture of cis- and trans-3-bromopyrrolidines (54\% yield) via the intermediacy of a bicyclic aziridinium ion.
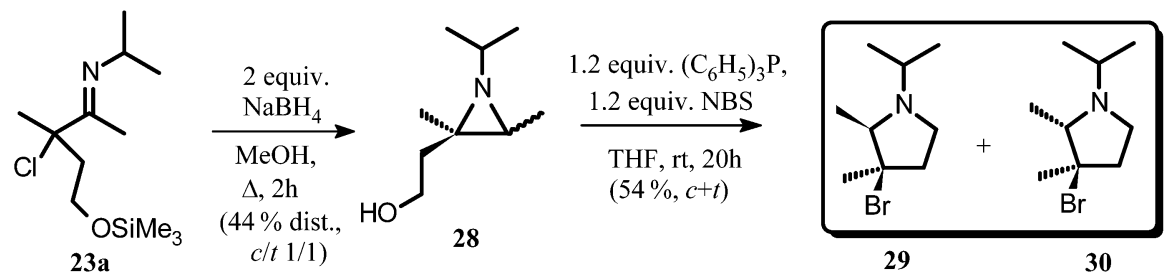

Scheme 8 


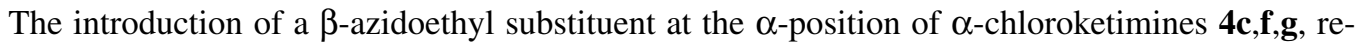
quires the addition of HMPA during the alkylation process (Scheme 9). The resulting $\gamma$-azido$\alpha$-chloroketimines 31a-c undergo conversion into pyrrolines 32a-c after reduction of the azido group by tin(II) chloride in methanol. Dehydrochlorination of the chloropyrrolines with sodium methoxide in methanol under reflux afforded pyrroles 33a-c in excellent yields. This method tolerates the presence of an extra chlorine in the starting imine so as to give rise to 3-chloro-2-arylpyrroles. The latter heterocycles have a great interest in agrochemistry as fungicides, bactericides, and acaricides [17].

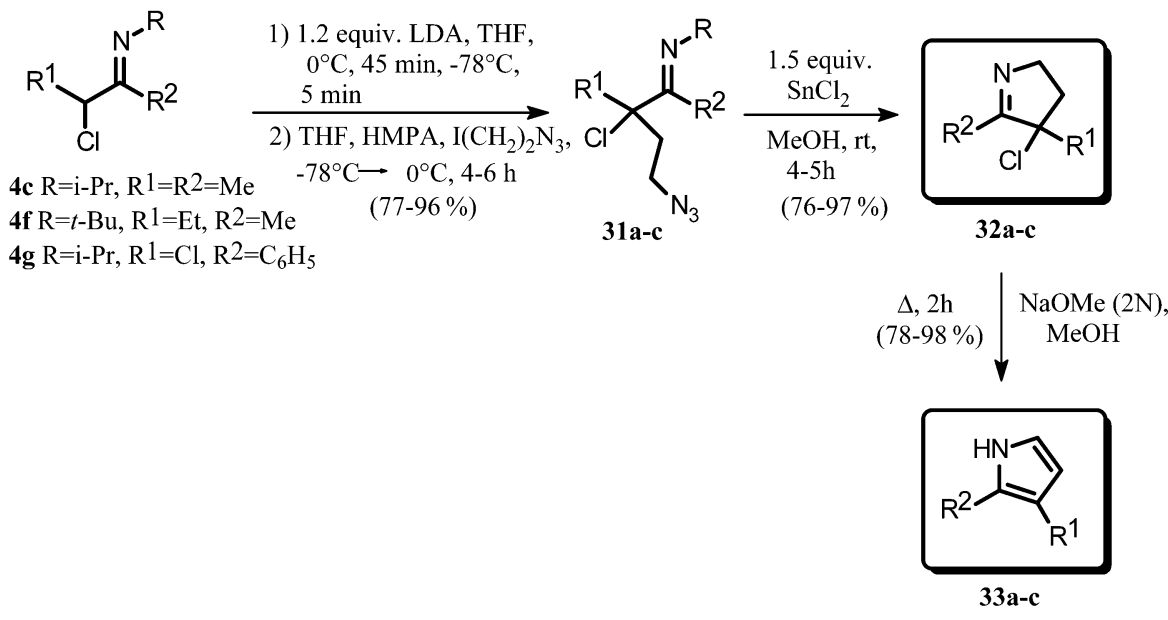

Scheme 9

Pyridines 36c and 37a,b,d were synthesized from $\alpha$-chloroketimines $\mathbf{4 c , f , g}$ and $\alpha$-bromoketimine 34 (Scheme 10) in the similar way by the utilization of 3-azido-1-iodopropane [18].<smiles>[R]N=C([R])C([R])[X]</smiles>

4c, $\mathrm{R}=\mathrm{i}-\mathrm{Pr}, \mathrm{R} 1=\mathrm{R} 2=\mathrm{Me}, \mathrm{X}=\mathrm{Cl}$ 4f, $\mathrm{R}=t$-Bu, $\mathrm{R} 1=\mathrm{Et}, \mathrm{R} 2=\mathrm{Me}, \mathrm{X}=\mathrm{Cl}$ 4g, $\mathrm{R}=\mathrm{i}-\mathrm{Pr}, \mathrm{R} 1=\mathrm{Cl}, \mathrm{R} 2=\mathrm{C}_{6} \mathrm{H}_{5}, \mathrm{X}=\mathrm{Cl}$ 34, $\mathrm{R}=\mathrm{i}-\mathrm{Pr}, \mathrm{R} 1=\mathrm{Me}, \mathrm{R} 2=4-\mathrm{MeC}_{6} \mathrm{H}_{4}, \mathrm{X}=\mathrm{Br}$

1) 1.2 equiv. LDA, THF, $0^{\circ} \mathrm{C}, 45 \mathrm{~min},-78^{\circ} \mathrm{C}, \mathrm{HMPA}, 5 \mathrm{~min}$

2) 1 equiv. $\mathrm{I}\left(\mathrm{CH}_{2}\right)_{3} \mathrm{~N}_{3},-78^{\circ} \mathrm{C} \longrightarrow 0^{\circ} \mathrm{C}, 4$ to $6 \mathrm{~h}$ $(62-100 \%)$

3) $\mathrm{R}^{2}=\mathrm{Me}: 1.5$ equiv. $\mathrm{SnCl}_{2}, \mathrm{MeOH}, \mathrm{rt}, 5 \mathrm{~h}$ $\mathrm{R}^{2}=\mathrm{C}_{6} \mathrm{H}_{5}: 1$ equiv. $\left(\mathrm{C}_{6} \mathrm{H}_{5}\right)_{3} \mathrm{P}, \mathrm{H}_{2} \mathrm{O}$, THF, rt, 20h $\mathrm{X}=\mathrm{Br}: 1) \mathrm{H}_{3} \mathrm{O}^{+} \quad \mathrm{R}^{1}=\mathrm{Cl}$ 2) 1 equiv. $\left(\mathrm{C}_{6} \mathrm{H}_{5}\right)_{3} \mathrm{P}$, pentane, $\mathrm{rt}, 6 \mathrm{~h} \underset{2 \mathrm{~N} \mathrm{NaOMe}}{3 \text { equiv. }}$ (35-62\%)
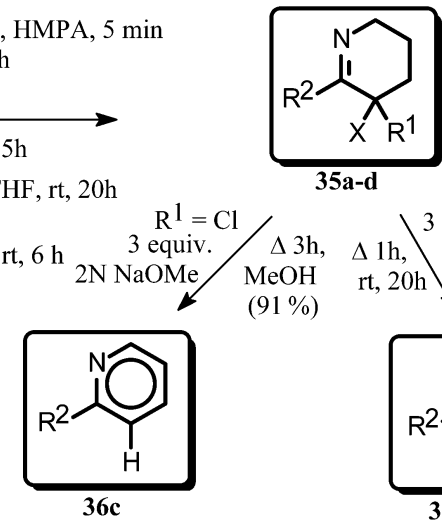

$35 a-d$ 3 equiv. $\Delta 3 \mathrm{~h}, \quad \Delta \mathrm{lh}, \quad$ KO- $t \mathrm{Bu}$, $\mathrm{MeOH}$ $(91 \%)$ $\mathrm{rt}, 20 \mathrm{~h} \stackrel{\mathrm{KO}-t \mathrm{Bu}, \mathrm{THF}}{\mathrm{T}}$

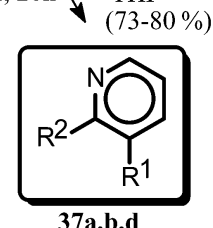

\section{Scheme 10}

3,3-Dichloro-1-azaallylic anions, derived from $\alpha, \alpha$-dichloroketimines $\mathbf{4 g}, \mathbf{h}$ by deprotonation with LDA, undergo an aldol reaction with aromatic aldehydes to give adducts, which, upon activation as mesylates, are conveniently converted into cis-3,3-dichloroazetidines 39a-c and 40a-c [19] by reaction with sodium borohydride or potassium cyanide (Scheme 11). The stereospecific formation of cis-azetidines 39a-c and 40a-c is explained by an Evans-type model of transition state, favoring the attack of the imino bond to occur from the site most remote from the larger substituent (Scheme 12). 
<smiles>[R]N=C(c1ccc([R])cc1)C(Cl)Cl</smiles>

4g R=i-Pr, $\mathrm{R} 1=\mathrm{H}$ 4h $\mathrm{R}=\mathrm{Et}, \mathrm{R} 1=\mathrm{Cl}$

1) 1.2 equiv. $\mathrm{LDA}$

THF, $0^{\circ} \mathrm{C} \rightarrow-15^{\circ} \mathrm{C}$

$\underset{2)}{\stackrel{4}{\mathrm{R}^{2} \mathrm{C}_{6} \mathrm{H}_{4} \mathrm{CHO}} \longrightarrow}$

$-15^{\circ} \mathrm{C} \rightarrow 0^{\circ} \mathrm{C}$

$1 \mathrm{~h}$ à $2.5 \mathrm{~h}$

3) 1.5 equiv. $\mathrm{MesCl}$, pyridine, rt, $5-20 \mathrm{~h}$

$(77-90 \%)$<smiles>[R]N=C(c1ccc([R4])c([R1])c1)C(Cl)(Cl)C(OC)c1ccc([R4])cc1</smiles>

$38 \mathrm{~b} R=\mathrm{Et}, \mathrm{R}^{1}-\mathrm{Cl}, \mathrm{R}^{2}$

38c $\mathrm{R}=$ $\mathrm{MeOH}, / 2$ equiv. 2 equiv.KCN, $\Delta, 20$ à $30 \mathrm{~h} \mathrm{NaBH}_{4}$ $(66-91 \%)$

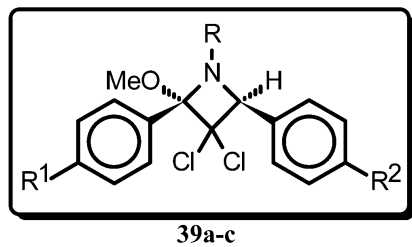

$\downarrow \Delta, 6-20 \mathrm{~h}$, (54-84\%)

Scheme 11<smiles>[R]N=C([R])C(Cl)(Cl)C([R1])[R]</smiles>

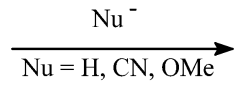

$\mathrm{R}=\mathrm{i}-\mathrm{Pr}, \mathrm{Et}$

$\mathrm{R}^{1}=\mathrm{C}_{6} \mathrm{H}_{5}, 4-\mathrm{ClC}_{6} \mathrm{H}_{4}$

$\mathrm{R}_{\mathrm{M}}=\mathrm{OMs}$

$\mathrm{R}_{\mathrm{L}}=\mathrm{C}_{6} \mathrm{H}_{5}, 4-\mathrm{MeC}_{6} \mathrm{H}_{4}$

Scheme 12

An alternative synthesis of 3,3-dichloroazetidines consists of the reduction of 3,3-dichloroazetidin-2-ones (41, Scheme 13) with chloroalane in ether under reflux [20]. These 3,3-dichloroazetidines $\mathbf{4 2}$ are convertible into 2 -azetines $\mathbf{4 3}$, which suffer a rearrangement during aqueous work-up to 2-benzoylaziridines [20].

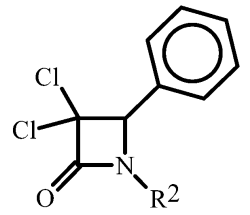

41

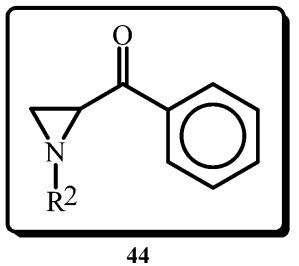

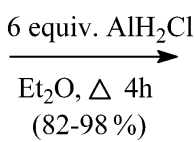

$(82-98 \%)$

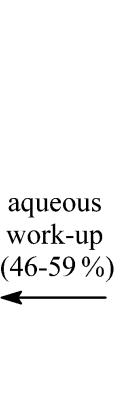

\section{Scheme 13}

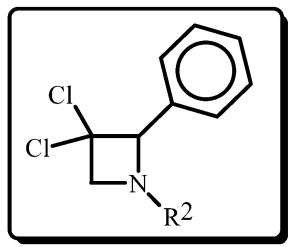

42

2 equiv. $\mathrm{NaH}$ DMSO, $3 \mathrm{~h}, 80^{\circ} \mathrm{C}$

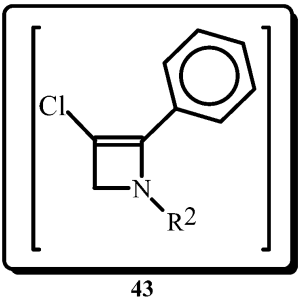

(C) 2003 IUPAC, Pure and Applied Chemistry 75, 1433-1442 
2-Azetines $\mathbf{4 3}$ are very strained endocyclic enamines in a four-membered ring system. Another type of strained enamine in a four-membered ring is the exocyclic enamine 46a,b (Scheme 14). A previous synthesis of such $\alpha$-methylene azetidine 46a,b proceeded by base-induced cyclization of $\beta$-chloroimines [21]. Another approach involves the reaction of $\beta$-lactams 45a,b with dimethyltitanocene in toluene [22]. Such methylenation of strained lactams is also possible with $\alpha$-lactams $\mathbf{4 8}$, but the yield of 2-methyleneaziridine $\mathbf{4 9}$ is only $30 \%$ (Scheme 15) [23].

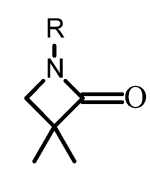

45a, $\mathrm{R}=\mathrm{C}_{6} \mathrm{H}_{5}$ 45b, $\mathrm{R}=4-\mathrm{ClC}_{6} \mathrm{H}_{4}$

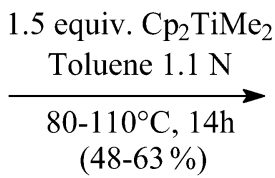

$(48-63 \%)$

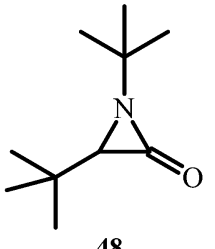

48

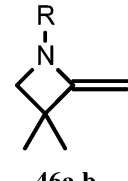

$46 a, b$<smiles>CC(=O)C(C)(C)CNc1ccccc1</smiles>
$\left(\mathrm{R}=\mathrm{C}_{6} \mathrm{H}_{5}\right)$

$(80 \%)$
$47 \mathbf{a}, \mathbf{b}$

Scheme 14

$$
\begin{gathered}
\begin{array}{c}
1.5 \text { equiv. } \mathrm{Cp}_{2} \mathrm{TiMe}_{2} \\
\text { Toluene } 1.1 \mathrm{~N}
\end{array} \\
\underset{80-100^{\circ} \mathrm{C}, 14 \mathrm{~h}}{(30 \%)}
\end{gathered}
$$

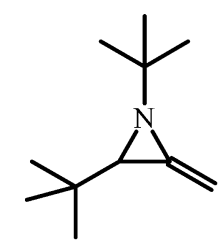

49

Scheme 15

In theory, it should be possible to react 3-halo-1-azaallylic anions 50a,b with a "OR" order to give rise to $\alpha$-chloro- $\alpha$-alkoxyketimines $\mathbf{5 1 a}, \mathbf{b}$, which should convert to $\alpha$-iminoketones $\mathbf{5 2} \mathbf{a}, \mathbf{b}$. The latter compounds hold the very important $\alpha$-iminoketo-functionality, which is essential for cracker flavor characteristics [24]. As such, these $\alpha$-iminoketones 52a-c are potential flavorants (Scheme 16). All attempts to put this idea in a useful reaction failed completely due to the fact that 3-halo-1-azaallylic anions 50a,b are not compatible with the oxidizing behavior of the reagents used. Oxidizing reagents such as dimethyldioxirane, bistrimethylsilylperoxide, benzoylperoxide $/ \mathrm{K}_{2} \mathrm{CO}_{3}, \mathrm{MoO}_{5}$. Pyridine.HMPA $(\mathrm{MoOPH})$ and 2-benzenesulfonyl-3-phenyloxaziridine did not give any suitable reaction as only tars were obtained under a variety of conditions. However, $\alpha$-bromoketimines $\mathbf{5 3 a}, \mathbf{b}$ could be converted in

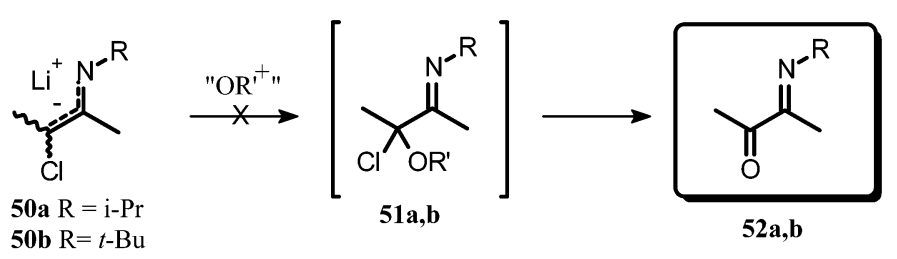

\section{Scheme 16}

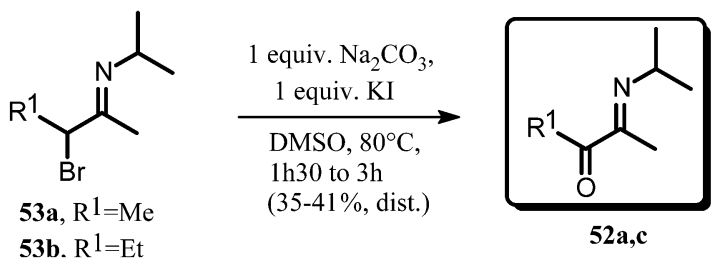


the desired $\alpha$-iminoketones 52a,c by a Kornblum-type reaction with sodium carbonate in DMSO in the presence of potassium iodide at $80^{\circ} \mathrm{C}$.

In summary, lithio 3-halo-1-azaallylic anions $\mathbf{5}$ have been proven to be suitable building blocks for organic synthesis. The protocol of regiospecific deprotonation of $\alpha$-haloketimines, subsequent reaction of 3-halo-1-azaallylic anions $\mathbf{5}$ with functionalized electrophiles, and cyclization of the resulting functionalized $\alpha$-haloketimines $\mathbf{6}$ proved to be a suitable method for the construction of a whole variety of heterocyclic compounds, including aziridines, azetidines, pyrrolidines, piperidines, pyrroles, pyridines, indoles, etc.

\section{ACKNOWLEDGMENTS}

The authors are indebted to the FWO-Flanders and to Ghent University (GOA) for financial support of this research.

\section{REFERENCES}

1. A. Krief. Tetrahedron 36, 2531 (1980).

2. (a) H. Weingarten, J. P. Chupp, W. A. White. J. Org. Chem. 32, 3246 (1967); (b) N. De Kimpe, R. Verhé, L. De Buyck, L. Moens, N. Schamp. Synthesis 22, 43 (1982).

3. (a) L. Duhamel and J. Y. Valnot. Tetrahedron Lett. 35, 3319 (1979); (b) N. De Kimpe, P. Sulmon, N. Schamp. Angew. Chem. 97, 878 (1985).

4. P. Sulmon, N. De Kimpe, N. Schamp. J. Org. Chem. 53, 4457 (1988).

5. J. T. Welch and K. V. Seper. J. Org. Chem. 53, 2991 (1988).

6. (a) N. De Kimpe and N. Schamp. Org. Prep. Proced. Int. 11, 115 (1979); (b) J. F. W. Keana and K. R. Schumaker. Tetrahedron 26, 5191 (1970); (c) N. De Kimpe, R. Verhé, L. De Buyck, N. Schamp. Bull. Soc. Chim. Belg. 84, 417 (1975); (d) N. De Kimpe, R. Verhé, L. De Buyck, Sunari Tukiman, N. Schamp. Tetrahedron 35, 789 (1979).

7. N. De Kimpe, R. Verhé, L. De Buyck, N. Schamp. Tetrahedron 26, 2709 (1985).

8. W. Aelterman, A. Eeckhaut, N. De Kimpe. Synlett 9, 1283 (2000).

9. (a) P. A. Grieco, M. Nishizawa, N. Marinovic, W. J. Ehmann. J. Am. Chem. Soc. 98, 7102 (1976); (b) D. F. Taber and B. P. Gunn. J. Org. Chem. 44, 450 (1979); (c) H. J. Bestmann, A. B. Attygalle, J. Glasbrenner, R. Riemer, O. Vostrowsky. Angew. Chem., Int. Ed. Engl. 26, 784 (1987); (d) H. J. Bestmann, A. B. Attygalle, J. Glasbrenner, R. Riemer, O. Vostrowsky, M. E. Costantino, G. Melikyan, E. D. Morgan. Liebigs Ann. Chem. 55 (1988).

10. N. De Kimpe and W. Aelterman. Tetrahedron 52, 12815 (1996).

11. R. G. Buttery. J. Agric. Food Chem. 21, 31 (1973).

12. (a) P. Werkhoff, W. Bretschneider, R. Emberger, M. Guentert, R. Hopp, M. Koepsel. Chem. Mikrobiol. Technol. Lebensm. 13, 30 (1991); (b) Chem. Abstr. 115, 7192r (1991).

13. W. Baltes. In Lebensmittelchemie, $3^{\text {rd }}$ ed., p. 277, Springer Verlag, Berlin (1992).

14. (a) T. Yanai, A. Furuhata, H. Sakakibara, K. Kojo. Jpn. Kokai Tokkyo Koho. JP 60, 136, 55, 3, (C1.C07C149/14), 20 July 1985; (b) Chem. Abstr. 104, 50077s (1986).

15. N. De Kimpe and W. Aelterman. J. Agric. Food Chem. 44, 3598 (1996).

16. N. De Kimpe, W. Aelterman, K. De Geyter, J. P. Declercq. J. Org. Chem. 62, 5138 (1997).

17. N. De Kimpe, K. Abbaspour Tehrani, C. Stevens, P. De Cooman. Tetrahedron 53, 3693 (1997).

18. W. Aelterman, N. De Kimpe, V. Tyvorskii, O. Kulinkovich. J. Org. Chem. 66, 53 (2001).

19. W. Aelterman and N. De Kimpe. J. Org. Chem. 63, 6 (1998).

20. Y. Dejaegher, S. Mangelinckx, N. De Kimpe. J. Org. Chem. 67, 2075 (2002).

21. P. Sulmon, N. De Kimpe, N. Schamp. J. Org. Chem. 63, 4462 (1998).

22. (a) K. Abbaspour Tehrani and N. De Kimpe. Tetrahedron Lett. 41, 1975 (2000); (b) N. De Kimpe and M. Boeykens. J. Org. Chem. 59, 5189 (1994). 
23. W. Aelterman. Ph.D. thesis, Ghent University, Ghent, Belgium, p. 84 (1998).

24. (a) W. Aelterman, N. De Kimpe, O. Kulinkovich. Bull. Soc. Chim. Belg. 106, 703 (1997); (b) J. Demyttenaere, K. Abbaspour Tehrani, N. De Kimpe. ACS Symposium Series 826, 150 (2002). 